\title{
In vitro seed germination and plantlet regeneration of Vanilla siamensis: An endemic species in Thailand
}

\author{
Vinan V. Chaipanich ${ }^{\mathrm{a}}$, David L. Roberts ${ }^{\mathrm{a}}$, Sureerat Yenchon $^{\mathrm{b}, \mathrm{c}, *}$, Sompong Te-chato ${ }^{\mathrm{b}, \mathrm{c}}$, \\ Minoo Divakaran ${ }^{\mathrm{d}}$ \\ ${ }^{a}$ Durrell Institute of Conservation and Ecology, School of Anthropology and Conservation, Faculty of \\ Social Sciences, University of Kent, Kent CT27NF, United Kingdom \\ b Agricultural Innovation and Management Division, Faculty of Natural Resources, Prince of Songkla \\ University, Songkhla 90110 Thailand \\ c Center of Excellent in Agricultural and Natural Resources Biotechnology (CoE-ANRB): phase 3, Faculty \\ of Natural Resources, Prince of Songkla University, Songkhla 90110 Thailand \\ d Department of Botany, Providence Women's College, Kozhikode, Kerala 673009 India
}

*Corresponding author, e-mail: sureerat.y@psu.ac.th

Received 16 Jul 2019

Accepted 9 May 2020

\begin{abstract}
This study reports the in vitro germination of self-pollinated pod of Vanilla siamensis, native to Thailand. The aim of the present work is to determine the effect of culture media and plant growth regulators on seed germination and plantlet regeneration. The vanilla seeds were asymbiotically germinated on different culture media under aseptic conditions. The results showed that, New Dogashima medium (NDM) supplemented with 2\% (w/v) sucrose, 15\% $(\mathrm{v} / \mathrm{v})$ coconut water $(\mathrm{CW})$ and $0.7 \%(\mathrm{w} / \mathrm{v})$ agar gave the highest levels of seed germination at $10.1 \%$. The fastest and highest percentage seed germination was achieved using NDM supplemented with $2 \mathrm{mg} / 1$ gibberellic acid $\left(\mathrm{GA}_{3}\right)$. Seeds on this culture medium germinated within 7-8 weeks in comparison with 10-11 weeks on culture medium without plant growth regulators. Protocorms were transferred to different culture media with various concentrations of 6benzyladenine (BA) to assess the protocorm development. The results revealed that $1 / 2$ Murashige and Skoog ( $1 / 2$ MS) medium gave the higher result in survival rate of protocorm than NDM. 1/2 MS medium with $0.5 \mathrm{mg} / 1$ BA was suitable for shoot formation. Plantlet development was completed after subculturing on $1 / 2 \mathrm{MS}$ medium supplemented with $0.5 \mathrm{mg} / 1 \alpha$-naphthaleneacetic acid (NAA) for 8 weeks and successfully acclimatized at $91.7 \%$. The protocol outline here can be used for mass propagation of this endangered species and used as a guideline for improvement of $V$. siamensis and its in vitro conservation.
\end{abstract}

KEYWORDS: Vanilla siamensis, seed germination, orchidaceae, protocorm, shoot induction

\section{INTRODUCTION}

The genus Vanilla is a cosmopolitan genus of orchid found throughout tropical regions. Although the genus is comprised of 110 species, the commercial vanilla production is mostly made up from the Vanilla planifolia which is originated from Mexico. Vanilla is commercially cultivated for its pods and its extract is used for flavouring [1]. While V. planifolia is originated in Mexico, it is now widely cultivated in many other countries including Madagascar, Indonesia, the Philippines, Papua New Guinea, Fiji, Jamaica, Costa Rica and Peninsular India, which make up $90 \%$ of the world's production [2]. The product of vanilla, vanillin, is widely used in a variety of industries including food, pharmaceuticals and cosmetics [3]. It is the second most expensive spice in the world after saffron. In addition, vanilla is unique within the Orchidaceae as it is the member of the family to produce edible fruits.

Within South East Asia, V. siamensis (Rolfe ex Dawnie) is one of the many thick-leafed species among five species found in Thailand (others are Vanilla albida, Vanilla aphylla, Vanilla griffithii and Vanilla pilifera) [4]. Flowers of $V$. siamensis can be differentiated from other species by the presence of finger-like hairs at the apex of the labellum. Within Thailand, $V$. siamensis is locally abundant in evergreen, dry evergreen and tropical forests, at 500-1200 m above sea level [5]. V. siamensis like other species of vanilla, it produces a climbing vine that will climb up the trunk into the canopy before cascade downward. However, anthropogenic 
pressures have resulted in the rapid decline in the natural habitat and as a consequent a reduction in the number of $V$. siamensis. According to the declination of this species it is worth for conservation for further use as important biomedical products. Recently, it has been shown that extracts from the fruits of $V$. siamensis exhibit characteristic effects of a natural bone promoting compounds such as phytoestrogen [6].

Generally, vanilla is propagated by stem cutting of mature vine. By this method, variation of vanilla for further improvement is not feasible. Continuous clonal propagation leads to monoculture making vanilla susceptible to diseases and pests [7]. At present, the application of biotechnological tools to questions concerning vanilla has focused mainly on the development of in vitro multiplication methods as alternative propagation and germplasm storage in vitro [8]. For breeding purposes, vanilla can be grown from seeds [9-11]. Thus, in vitro seed germination is necessary due to low seed production, hard seed coat and low germination under natural conditions. Standardization of tissue culture technique can be used to solve those problems of propagation $[12,13]$. At present, the in vitro germination and plantlet regeneration of $V$. siamensis are still limited, however a better understanding of the technique can be used for the improvement and in vitro conservation of vanilla. The aim of the present work is to study the effect of culture media and plant growth regulators (PGRs) on vanilla seed germination and plantlet regeneration.

\section{MATERIALS AND METHODS}

\section{Chemicals and materials}

$\mathrm{GA}_{3}$, BA and NAA were purchased from SigmaAldrich (St. Louis, MO, USA). AC was from DC Fine Chemicals, Spain. CW and coconut husk were obtained from coconut palms planted in Khlong Hoi Khong Reserach Station, Prince of Songkla University. The compost mixture containing top soil and green waste was obtained from Khlong Hoi Khong Reserach Station, Prince of Songkla University.

\section{Plant materials}

Vanilla beans were collected from Chiang Mai University in Chiang Mai province, northern Thailand. Green vanilla beans were harvested at 10 months after hand pollination. They were cleaned by washing with running tap water for a few minutes, then cut open vertically and the seeds were removed and placed onto filter paper. The seeds were surface ster- ilized by dipping in $15 \%$ (v/v) sodium hypochlorite $(\mathrm{NaOCl})$ solution containing $0.5 \%(\mathrm{v} / \mathrm{v})$ Tween 20 for $10 \mathrm{~min}$, after which the seeds were then rinsed three times with sterile distilled water.

\section{Effect of culture media on seed germination}

To determine the influence of culture media on seed germination subsequent to protocorm development, sterilized seeds were placed onto New Dogashima medium (NDM) [14] or $1 / 2$ Murashige and Skoog (1/2 MS) [15] or Vacin and Went (VW) [16] medium supplemented with $2 \%(\mathrm{w} / \mathrm{v})$ sucrose, $15 \%(\mathrm{v} / \mathrm{v})$ coconut water (CW) and $0.7 \%(\mathrm{w} / \mathrm{v})$ agar, with or without $0.2 \%(\mathrm{w} / \mathrm{v})$ activated charcoal (AC). After culture for 10 weeks, percentage of seed germination was calculated from the number of germinated seeds divided by the total number of cultured seeds and multiplied by 100. All experiments consisted of three independent replicates with 10 culture bottles per replicate, 60 seeds per bottle.

\section{Effect of plant growth regulators (PGRs) on seed germination}

Based on the results of the previous experiments, the most suitable medium was selected and used for further investigation. To determine the influence of PGRs on enhancement of seed germination frequency, vanilla pod was clean by the same processes as mentioned in the previous experiment. The sterilized seeds were then placed onto NDM supplemented with $2 \%(\mathrm{w} / \mathrm{v})$ sucrose, $15 \%(\mathrm{v} / \mathrm{v}) \mathrm{CW}$, $0.7 \%(\mathrm{w} / \mathrm{v})$ agar and various concentrations $(0,1$, $2 \mathrm{mg} / \mathrm{l})$ of gibberellic acid $\left(\mathrm{GA}_{3}\right)$ or 6-benzyladenine (BA). After culture, seed data was recorded every week. Percentage of seed germination was calculated as above. All experiments consisted of three independent replicates with 10 culture bottles per replicate, 60 seeds per bottle.

\section{Effect of culture media on survival rate of protocorm}

To determine the influence of culture media on survival rate of protocorm, protocorms obtained from NDM supplemented with $2 \mathrm{mg} / 1 \mathrm{GA}_{3}$ were transferred to NDM or $1 / 2 \mathrm{MS}$ medium supplemented with $2 \mathrm{mg} / 1 \mathrm{BA}, 2 \%$ (w/v) sucrose, $15 \%$ (v/v) CW and $0.7 \%(\mathrm{w} / \mathrm{v})$ agar. After culture, percentage of survival rate of protocorms was recorded every week. All experiments consisted of three independent replicates with 8 culture bottles per replicate and 4 protocorms per bottle. 


\section{Effect of concentrations of BA on shoot induction}

To determine the influence of concentration of BA on shoot induction, the protocorms were transferred to $1 / 2$ MS medium supplemented with various concentrations of BA $(0,0.125,0.25,0.5,1.0$, $2.0 \mathrm{mg} / \mathrm{l}), 2 \%(\mathrm{w} / \mathrm{v})$ sucrose, $15 \%(\mathrm{v} / \mathrm{v}) \mathrm{CW}$ and $0.7 \%(\mathrm{w} / \mathrm{v})$ agar. After 8 weeks of culture, percentage of protocorm forming shoots was calculated. All experiments consisted of three independent replicates with 8 culture bottles per replicate and 4 protocorms per bottle.

\section{Effect of concentrations of naphthaleneacetic acid (NAA) on root induction}

To determine the influence of concentrations of NAA on root formation, the shoots of $1.5-3 \mathrm{~cm}$ in height were transferred to $1 / 2$ MS medium supplemented with various concentrations of NAA $(0,0.25,0.5$, $1.0,2.0 \mathrm{mg} / \mathrm{l}), 2 \%(\mathrm{w} / \mathrm{v})$ sucrose, $15 \%(\mathrm{v} / \mathrm{v}) \mathrm{CW}$ and $0.7 \%(\mathrm{w} / \mathrm{v})$ agar. Percentage of shoot with roots and number of roots per shoot were recorded after 8 weeks of culture. All experiments consisted of three independent replicates with 8 culture bottles per replicate and 4 shoots per bottle.

\section{Culture conditions}

All cultures were maintained at $25 \pm 1^{\circ} \mathrm{C}$ under a $16 \mathrm{~h}$ photoperiod with light supplied by cool-white fluorescent lamps at an intensity of $10 \mu \mathrm{mol} \mathrm{m} \mathrm{m}^{-2} \mathrm{~s}^{-1}$ photosynthetic photon flux density (PPFD).

\section{Acclimatization of plantlets}

The in vitro plantlets with well-developed roots were removed from culture vessel, washed thoroughly in running tap water to remove residual agar medium before transfer to sand:compost mixture:coconut husk $(1: 1: 2)$ in 4 -inch plastic pots. The plants were grown in a shaded house under $80 \%$ shading with three replications (24 plants per replication). Percentage of survival plantlets was recorded after 8 weeks of transplanting.

\section{Statistical analysis}

The experiments were set up in completely randomized design (CRD). The test of significant differences among treatments were subjected to ANOVA and determined using Duncan's multiple range test (DMRT). All statistical analyses were performed using the R Software, version 2.14.0.

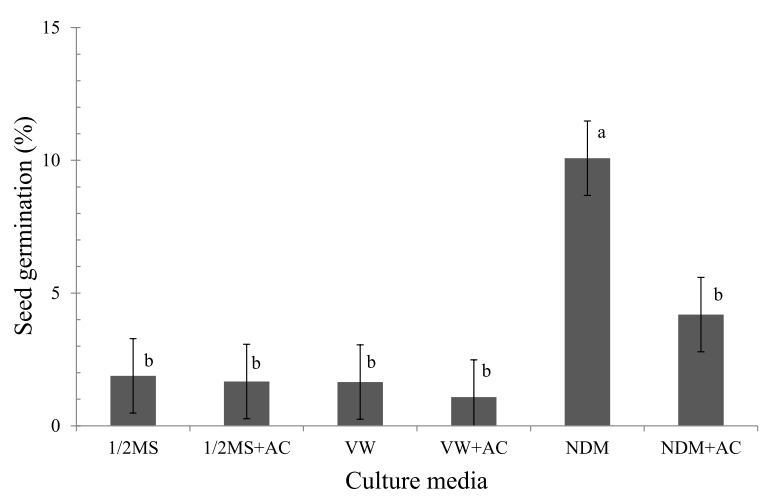

Fig. 1 Percentage of seed germination after culturing on different culture media with and without activated charcoal (AC) for 12 weeks. Bars correspond to standard error (SE) of means. Values with different letters are significantly different $(p \leqslant 0.01)$.

\section{RESULTS \\ Effect of culture media on seed germination}

After 12 weeks of culture, seed germinated from all tested culture media was observed, but the percentage of germination significantly differed. The seeds cultured on NDM supplemented with $2 \%$ (w/v) sucrose, $15 \%(\mathrm{v} / \mathrm{v}) \mathrm{CW}$ and $0.7 \%(\mathrm{w} / \mathrm{v})$ agar gave the highest level of seed germination (10.1\%). In the same culture medium, seed germination rate in the medium without AC was higher compared to medium containing $0.2 \%(\mathrm{w} / \mathrm{v})$ AC (Fig. 1). The result indicates that, the germination process started approximately about 9 weeks after culturing. After this period the embryo continued growing larger, seed coat would burst and embryo emerged from the seed coat and rhizoids appeared (arrow) (Fig. 2ab). Twelve weeks after culturing, protocorm with shoot apex and leaf primordial continued to grow. When the protocorm reached about $2 \mathrm{~mm}$ in length, it turned into green color (Fig. 2c-d).

\section{Effect of plant growth regulators (PGRs) on seed germination}

The effect of PGRs on seed germination after culturing on NDM supplemented with $2 \%(\mathrm{w} / \mathrm{v})$ sucrose, $15 \%(\mathrm{v} / \mathrm{v}) \mathrm{CW}$ and $0.7 \%(\mathrm{w} / \mathrm{v})$ agar were shown in Fig. 3. The fastest and highest levels of seed germination were obtained on this medium supplemented with $2 \mathrm{mg} / 1 \mathrm{GA}_{3}$. Seeds on $\mathrm{GA}_{3}$ containing medium germinated within 7-8 weeks in comparison with 10-11 weeks on the same medium without plant growth regulators. After 10 weeks of culture, the highest percentage of seed germination 

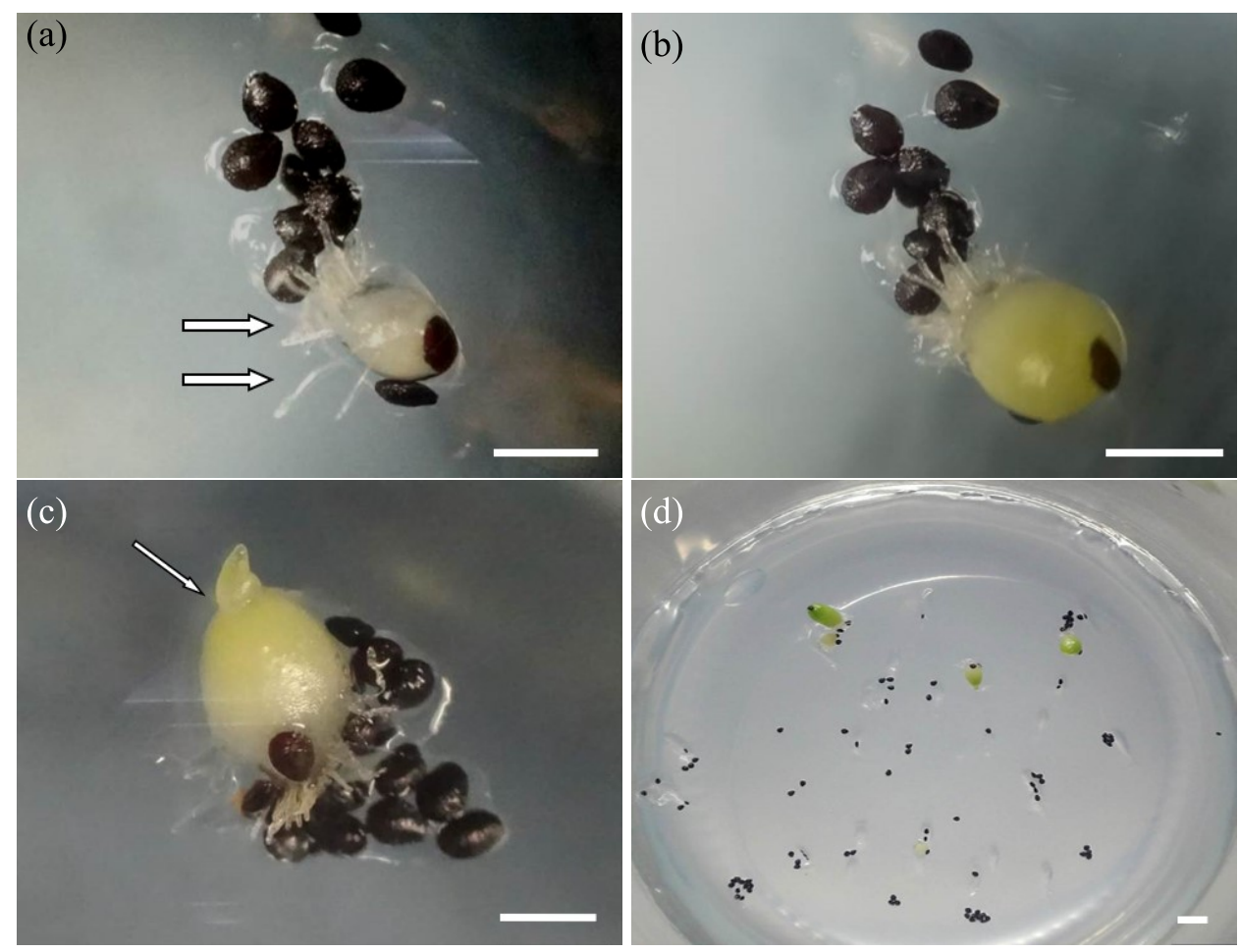

Fig. 2 Germination of vanilla seeds on NDM showing the enlargement of embryo and rhizoids (arrows) formed on the surface of the protocorm after 10 weeks of culture (a), 11 weeks of culture (b), development of protocorm with shoot apex (arrow) after 12 weeks of culture (c-d) (bar $=2 \mathrm{~mm})$.

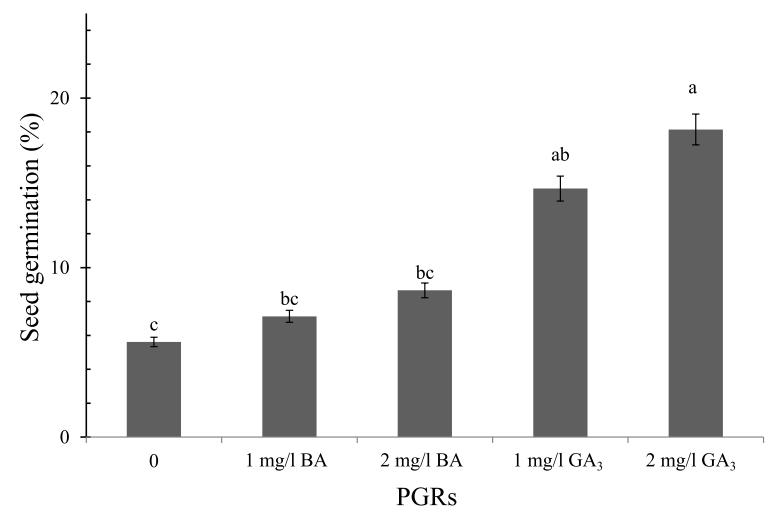

Fig. 3 Percentage of seed germination after culturing on NDM supplemented with various PGRs at different concentrations for 10 weeks. Bars correspond to SE of means. Values with different letters are significantly different $(p \leqslant 0.01)$.

was observed (18.2\%). Both concentrations of $\mathrm{GA}_{3}$ were equally effective on seed germination but far different from that obtained from BA and PGR-free containing medium. The seed germination rate in the medium without PGRs was the lowest (5.6\%)

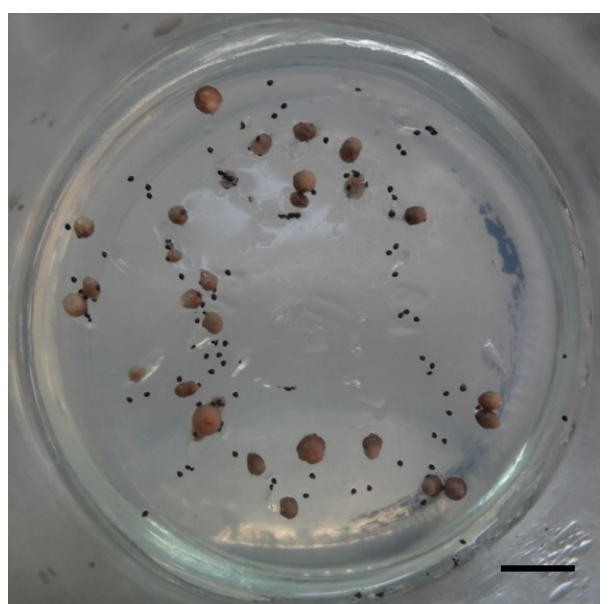

Fig. 4 Seed germination on NDM with $2 \mathrm{mg} / 1 \mathrm{GA}_{3}$ after 10 weeks of culture with some protocorm turning brown and dying after culture for further 4 weeks (bar $=0.5 \mathrm{~cm}$ ).

(Fig. 3). Although, the highest germination level was observed on $\mathrm{GA}_{3}$ containing medium, however protocorm remained yellow with some turned into brown color and died after germination for 4 weeks (Fig. 4). 


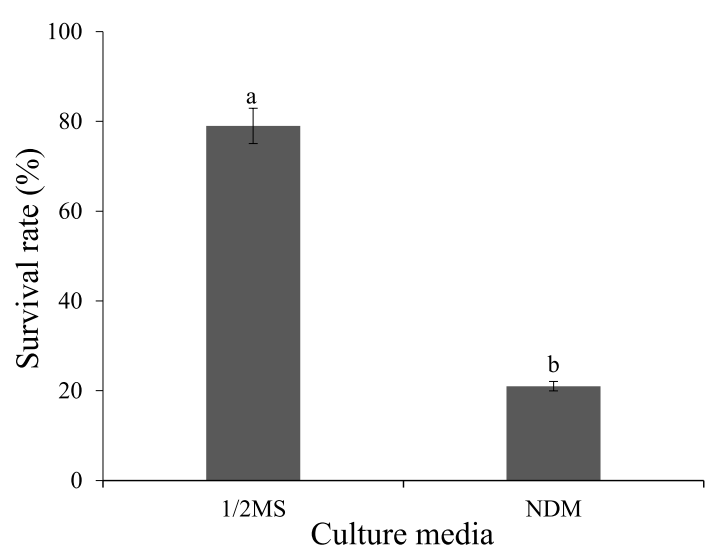

Fig. 5 Survival rate of protocorms after culturing on $1 / 2$ MS and NDM for 6 weeks. Bars correspond to SE of means. Values with different letters are significantly different $(p \leqslant 0.01)$.

\section{Effect of culture media on survival rate of protocorm}

The role of culture media on survival rate of protocorm was presented in Fig. 5. The component of nutrient in culture media showed a significant effect on the survival rate of protocorm. At 6 weeks after culturing, protocorms cultured on $1 / 2$ MS medium had a survival rate of $79 \%$, higher than those on NDM (21\%) (Fig. 5). In $1 / 2$ MS medium, protocorms showed the development of the scale-like leaf primordial and developed into shoot, whereas protocorms on NDM had not change. The sizes of protocorms were still the same as initial culture. Thus, $1 / 2$ MS medium was found to be the best choice for promoting the development of protocorm into shoot formation.

\section{Effect of concentrations of BA on shoot formation}

After 8 weeks of culture, protocorm on a culture medium with BA showed a higher survival rate than culture medium without BA. Significant differences were observed among concentrations of BA for survival rate, shoot formation and number of shoots (Table 1$)$. The highest survival rate $(96.7 \%)$ was observed when protocorms were cultured on $1 / 2 \mathrm{MS}$ medium supplemented with $0.5-1 \mathrm{mg} / 1 \mathrm{BA}$. BA at $2 \mathrm{mg} / \mathrm{l}$ exhibited the highest multiplication of shoot at $100 \%$, followed by 0.5 and $1.0 \mathrm{mg} / \mathrm{l} \mathrm{BA}(93.3$ and $96.7 \%$, respectively). The number of shoots per explant was not significantly different. Thus, the culture medium with $0.5 \mathrm{mg} / 1 \mathrm{BA}$ was suitable for shoot formation.
Table 1 Effect of BA concentrations on survival rate and shoot formation of $V$. siamensis after culturing on $1 / 2$ MS for 8 weeks.

\begin{tabular}{|c|c|c|c|}
\hline $\begin{array}{l}\text { BA } \\
(\mathrm{mg} / \mathrm{l})\end{array}$ & $\begin{array}{l}\text { Survival } \\
\text { rate (\%) }\end{array}$ & $\begin{array}{c}\text { Shoot } \\
\text { formation }(\%)\end{array}$ & $\begin{array}{l}\text { No. of shoots } \\
\text { /explant }\end{array}$ \\
\hline 0 & $73.33 \pm 5.77^{c}$ & $0.00 \pm 0.00^{d}$ & $1.33 \pm 0.5$ \\
\hline 0.125 & $76.67 \pm 15.27^{\mathrm{bc}}$ & $23.33 \pm 11.54^{\mathrm{c}}$ & $1.67 \pm 0.5$ \\
\hline 0.25 & $83.33 \pm 11.55^{a b c}$ & $73.33 \pm 11.54^{b}$ & $2.00 \pm 1.0$ \\
\hline 0.5 & $96.67 \pm 5.77^{\mathrm{a}}$ & $93.33 \pm 5.77^{\mathrm{a}}$ & $2.00 \pm 1.0$ \\
\hline 1.0 & $96.67 \pm 5.77^{\mathrm{a}}$ & $96.67 \pm 5.77^{\mathrm{a}}$ & $2.67 \pm 0.5$ \\
\hline 2.0 & $93.33 \pm 11.54^{\mathrm{ab}}$ & $100.00 \pm 0.00^{\mathrm{a}}$ & $2.33 \pm 0.5$ \\
\hline F-test & $* *$ & $* *$ & ns \\
\hline C.V. (\%) & 11.5 & 11.6 & 37.3 \\
\hline
\end{tabular}

Table 2 Effect of NAA concentrations containing $1 / 2$ MS on root formation and number of roots of $\mathrm{V}$. siamensis after culturing for 8 weeks.

\begin{tabular}{lcc}
\hline NAA (mg/l) & Root formation (\%) & No. of roots/shoot \\
\hline 0 & $58.33 \pm 14.44^{\mathrm{b}}$ & $1.33 \pm 0.33$ \\
0.25 & $83.33 \pm 14.44^{\mathrm{a}}$ & $1.45 \pm 0.38$ \\
0.5 & $100 \pm 0.00^{\mathrm{a}}$ & $1.55 \pm 0.38$ \\
1.0 & $100 \pm 0.00^{\mathrm{a}}$ & $1.67 \pm 1.15$ \\
2.0 & $100 \pm 0.00^{\mathrm{a}}$ & $1.67 \pm 0.57$ \\
\hline F-test & $* *$ & $\mathrm{~ns}$ \\
C.V. $(\%)$ & 10.3 & 42.0 \\
\hline \multicolumn{2}{c}{$* *$ significantly different at $p \leqslant 0.01, \mathrm{~ns}=$ not } \\
\multicolumn{2}{l}{ significantly different. Values are means \pm standard } \\
deviation, those followed by the same letters within \\
\multicolumn{2}{l}{ a column are not significantly different. }
\end{tabular}

\section{Effect of concentrations of NAA on root induction}

After 8 weeks of culture, root induction on culture medium with NAA showed better results than culture medium without NAA. Significant differences were observed among concentrations of NAA for root formation. The highest root formation (100\%) was observed when shoots were cultured on $1 / 2$ MS medium supplemented with $0.5 \mathrm{mg} / 1$ NAA significantly different with medium without NAA (Table 2). Complete plantlets were obtained after culturing on $1 / 2$ MS medium supplemented with $0.5 \mathrm{mg} / 1 \mathrm{NAA}$ for 8 weeks and successfully acclimatized at $91.7 \%$ (Fig. 6). 

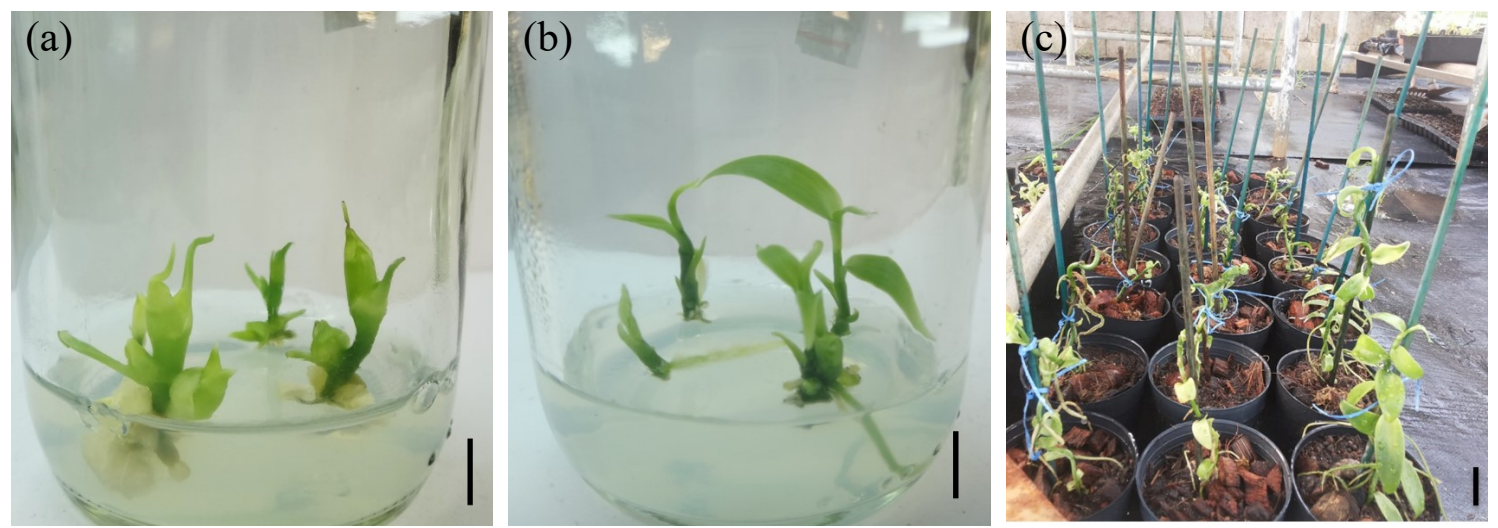

Fig. 6 Shoot formation on $1 / 2$ MS medium containing $2 \mathrm{mg} / 1 \mathrm{BA}$ (a), complete plantlets after culturing on $1 / 2$ MS with $0.5 \mathrm{mg} / 1$ NAA for 8 weeks (b) and survival plantlets after 4 months of acclimatization (c) $(\mathrm{bar}=1 \mathrm{~cm})$.

\section{DISCUSSION}

There are many different culture media use for asymbiotic germination of orchid, including MS, VW, Kundson (KC) and NDM. Like the seeds of other orchid species, Vanilla species produce many small seeds without endosperm, they have low germination rate under natural conditions and as such there is a nutrient requirement for initiation of germination $[17,18]$. The results from this study showed that NDM medium provided a good germination rate of $V$. siamensis seed while prolonging survival rate of the protocorm probably due to the high contents of mineral in medium. MS medium with a reduction of constituents to half its original strength $(1 / 2 \mathrm{MS})$ has been reported to give a good response in protocorm development [19]. However, full strength MS medium gave better results than KC medium, for in vitro culture of vanilla, the minimum germination (26\%) was observed in $1 / 2$ MS and maximum (85\%) was recorded in full strength MS medium supplemented with $2 \mathrm{~g} / 1$ tryptone [20]. Furthermore, addition of activated charcoal in all culture media decreased the seed germination. Normally, activated charcoal can provide a dark environment and adsorb substances presumed to be deleterious and/or inhibitory to in vitro culture, but adsorption of growth regulators being supplied to the tissue by activated charcoal could also occur at the same time [21-23]. However, in some orchids, activated charcoal plays also an important role in seed germination. The addition of activated charcoal had a positive influence on protocorm size and development [24].

The plant growth regulators, $\mathrm{BA}$ and $\mathrm{GA}_{3}$ are important in regulating numerous plant growth and developmental processes [25]. Adding $\mathrm{GA}_{3}$ in cul- ture medium increased the percentage of germination. Seeds on this medium germinated within 7-8 weeks compared to 10-11 weeks on medium without plant growth regulators. $\mathrm{GA}_{3}$ plays a significant role in flower development, fruit development, shoot elongation and is known to stimulate seed germination in a wide range of plant species [26]. The result is similar to the findings in Comparettia falcata in which seed germination showed a positive correlation with $\mathrm{GA}_{3}$ concentration. There was an increase in percentage of germinated seeds in the sixth weeks [27]. This might be due to effectiveness of $\mathrm{GA}_{3}$, which at higher concentrations overcome dormancy, causing rapid germination of seed. Higher concentration of $\mathrm{GA}_{3}$ was proved to be more effective than lower concentration. On the other hand, the changes in the characteristics of the cellular membrane and the cell wall can regulate the materials required for growth during their cultures [27]. However, the present study indicated that percentage of germination was low, which might be caused by the hard seed coat of vanilla seeds. To activate a higher percentage of seed germination, further research should focus on pre-treatment of seed as a pre-culture method.

For shoot induction, the culture medium with BA was significantly different from culture medium without BA. BA is a cytokinin hormone, which affects cell division and shoots multiplication. Moreover, this study also showed the same corresponding result in shoot formation of $V$. planifolia, after 45 days of culture, $1 \mathrm{mg} / 1 \mathrm{BA}$ showed the highest shoot multiplication at 6.06 shoots/explant [19]. A mean number of 4.2 shoots per callus was produced on medium containing $1.0 \mathrm{mg} / 1 \mathrm{BA}$ and $0.5 \mathrm{mg} / 1 \mathrm{NAA}$ with a mean shoot length at $3.8 \mathrm{~cm}$ after 8 weeks 
of culture [28]. Shoots were only formed from the callus of $V$. planifolia when the medium was supplemented with BA in addition to NAA, and no shoots were induced when either BA or NAA was applied alone [29]. BA at $1 \mathrm{mg} / 1$ combined with $1.5 \mathrm{mg} / \mathrm{l}$ kinetin (KN) gave the best result in shoot induction of $V$. planifolia [30].

In the case of root induction, culture medium with NAA showed higher rooting response than culture medium without NAA. This present study was in concurrence with Tan et al [28] who reported that, the highest rooting response $(88.3 \%)$ of $V$. planifolia was achieved on the medium supplemented with $1.0 \mathrm{mg} / 1 \mathrm{NAA}$ alone with a mean number of 3.3 roots per shoot and a mean length of $4.4 \mathrm{~cm}$. Moreover, this finding was similar with the study carried out by Janarthanam and Seshadri [29], where the rooting response in V. planifolia was suppressed with an increase in concentrations of NAA. In this study, complete plantlets were successfully acclimatized at the rate of $91.7 \%$. High percentage of acclimatization was also obtained in V. planifolia [29-31]

In conclusion, NDM is suggested for seed germination. 1/2 MS medium supplemented with $0.5 \mathrm{mg} / 1$ BA was suitable for shoot formation. For root induction, $1 / 2$ MS medium supplemented with $0.5 \mathrm{mg} / 1$ NAA gave the best result. This is the first report of the successful in vitro germination of $V$. siamensis. Results of this study may have future applications for Vanilla plant breeding programs, opening the opportunity to develop new hybrids for the vanilla industry, as well as, for germplasm conservation of this important resource.

Acknowledgements: This work was supported by Prince of Songkla University [Grant no. NAT580931S] and Center of Excellence in Agricultural and Natural Resources Biotechnology (CoE-ANRB): phase 3, Faculty of Natural Resources, Prince of Songkla University.

\section{REFERENCES}

1. Geetha S, Sudheer AS (2000) In vitro propagation of Vanilla planifolia, a tropical orchid. Curr Sci 79, 886-889.

2. Sujatha S, Bhat R (2010) Response of vanilla (Vanilla planifolia A.) intercropped in arecanut to irrigation and nutrition in humid tropics of India. Agric Water Manag 97, 988-994.

3. Renuga G, Kumar SNS (2014) Induction of vanillin related compounds from nodal explants of Vanilla planifolia using BAP and Kinetin. Asian J Plant Sci 4, 53-61.

4. Wongsheree T, Wongs-Aree C, Srilaong V, Jitareerat
P (2013) Vanilla cultivation and curing in Thailand. Acta Hort 1011, 213-218.

5. Carmeron K (2011) Profiles of select Vanilla species. In: Appleegate S (ed) Vanilla Orchids: Natural History and Cultivation, Timber Press Inc, Portland, OR, pp 41-56.

6. Wanachantararak P, Thongpaeng J, Kantawong F, Boonchird C, Chairote G (2012) Effect of phytoestrogen activity on hFOB 1.19 osteoblast cells of Vanilla siamensis. $J$ Chem Chem Eng 6, 43-52.

7. Divakaran M, Nirmal Babu K, Ravindran PN, Peter KV (2015) Biotechnology for micropropagation and enhancing variations in Vanilla. Asian J Plant Sci Res 5, 52-62.

8. Gonzalez-Arnao MT, Lazaro-Vallejo CE, Engelmann F, Gamez-Pastrana R, Martinez-Ocampo YM, PastelinSolano MC, Diaz-Ramos C (2009) Multiplication and cryopreservation of vanilla (Vanilla planifolia Andrews). In Vitro Cell Dev Biol Plant 45, 574-582.

9. Knudson L (1950) Germination of seeds of vanilla. Am J Bot 37, 241-247.

10. Divakaran M, Nirmal BK, Peter KV, Ravindran PN (2006) Interspecific hybridization in Vanilla and molecular characterization of hybrids and selfed progenies using RAPD and AFLP markers. Sci Hort 108, 414-422.

11. Withner CL (1995) Ovule culture and growth of vanilla seedling. Amer Orchid Soc Bull 24, 381-392.

12. Chugh S, Guha S, Rao IU (2009) Micropropagation of orchids: a review on the potential of different explants. Sci Hort 122, 507-520.

13. Gu Z, Arditti J, Nyman LP (1987) Vanilla planifolia: callus induction and plantlet production in vitro. Lindleyana 2, 48-52.

14. Tokuhara K, Mii M (1993) Micropropagation of Phalaenopsis and Doritaenopsis by culturing shoot tips of flower stalk buds. Plant Cell Rep 13, 7-11.

15. Murashige T, Skoog F (1962) A revised medium for rapid growth and bioassays with tobacco cultures. Physiol Plant 15, 473-497.

16. Vacin EF, Went FW (1949) Some pH changes in nutrient solutions. Bot Gaz 110, 605-613.

17. Alomia YA, Munoz E, Acosta-Rangel AM, Otero JT (2016) Morphometric analysis of Vanilla seeds (Orchidaceae) by microscopic techniques. Lankesteriana 16, 21-26.

18. Alomia YA, Mosquera-Espinosa AT, Flanagan NS, Otero JT (2017) Seed viability and symbiotic seed germination in Vanilla spp. (Orchidaceae). Res $J$ Seed Sci 10, 43-52.

19. Zuraida AR, Liyana KHF, Nazreena OA, Wan WS, Che CMZ, Zamri Z, Sreeramanan S (2013) A simple and efficient protocol for the mass propagation of Vanilla planifolia. Am J Plant Sci 4, 1685-1692.

20. Divakaran M (2002) Seedling and somaclonal variation and their characterization in Vanilla. PhD thesis. Univ of Calicut, Kerala, India. 
21. Pan MJ, Staden JV (1998) The used of charcoal in in vitro culture: A review. Plant Growth Regul 26, 155-163.

22. Moraes LM, Faria RT, Cuquel FL (2005) Activated charcoal for in vitro propagation of Brazilian orchids. Acta Hort 683, 383-390.

23. Wang PJ, Huang LC (1976) Beneficial effects of activated charcoal on plant tissue and organ cultures. In Vitro Cell Dev Biol Plant 12, 260-262.

24. Bieniek AP, Dyduch-Sieminska M, Rudas M (2010) Influence of activated charcoal on seed germination and seedling development by the asymbiotic method in Zygostates grandiflora (Lindl.) Mansf. (Orchidaceae). Folia Hortic 22, 45-50.

25. de Pauw MA, Remphrey WR, Palmer CE (1995) The cytokinin preference for in vitro germination and protocorm growth of Cypripedium candidum. Ann Bot 75, 267-275.

26. Thomas SG, Rieu I, Steber CM (2005) Gibberellin metabolism and signaling. Vitam Horm 72, 289-338.

27. Pedroza-Manrique J, Fernandez-lizarazo C, Suarez-
Silva A (2005) Evaluation of the effect of three growth regulators in the germination of Comparettia falcata seeds under in vitro conditions. In Vitro Cell Dev Biol Plant 41, 838-843.

28. Tan BC, Chin CF, Alderson P (2011) Optimization of plantlet regeneration from leaf and nodal derived callus of Vanilla planifolia Andrews. Plant Cell Tiss Org Cult 105, 457-463.

29. Janarthanam B, Seshadri S (2008) Plantlets regeneration from leaf derived callus of Vanilla planifolia Andr. In Vitro Cell Dev Biol Plant 44, 84-89.

30. Abebe Z, Mengesha A, Teressa A, Tefera W (2009) Efficient in vitro multiplication protocol for Vanilla planifolia using nodal explants in Ethiopia. Afr $J$ Biotechnol 8, 6817-6821.

31. Ramos-Castellá A, Iglesias-Andreu LG, Bello-Bello J, Lee-Espinosa H (2014) Improved propagation of vanilla (Vanilla planifolia Jacks. ex Andrews) using a temporary immersion system. In Vitro Cell Dev Biol Plant 50, 576-581. 